\title{
An introduction to a theory on the role of $\pi$-electrons of docosahexaenoic acid in brain function ${ }^{\star}$ The Quantum Brain
}

\author{
Crawford MA*, Thabet $\mathrm{M}$ and Wang $\mathrm{Y}$ \\ Institute of Brain Chemistry and Human Nutrition, and Department of Cancer and Surgery, Chelsea and Westminster Hospital \\ Campus of Imperial College, London, Room H3,34, 369 Fulham Road, London SW10 9NH, UK
}

Received 24 December 2017 - Accepted 7 February 2018

\begin{abstract}
In Part I, we discuss the background to views on brain function and our thesis that it is conducted by $\pi$-electrons which perform sensory reception, memory, action, cognition and consciousness. Our thesis is consistent with the classical views of ion movement and synaptic protein strengthening. However, protein based views contain no element of precision for the signal. Precision is essential for true signal transduction of sensory input and the faithful execution of learnt neural pathways. In Part II, we incorporate these principles to discuss the mechanism whereby electron function adds precision of signal energy to the process through the Pauli Exclusion Principle. The Huxley-Hodgkin (HH) account of neural function describes the movement of sodium, potassium and calcium ions to create electrochemical potentials across membranes with well-established mathematical and experimental support. To explain learning, consciousness and perception, others have claimed brain function depends on protein synthesis or RNA coding. Some consider super position and collapse as the computational mechanism. This however is fragile with no mechanism described to protect from natural collapse and decoherence at the temperatures of the brain. A novel approach was adopted by Penrose and Hammeroff who describe consciousness as a function of 'objective reduction' ('OR') of the quantum state. This orchestrated OR activity ('Orch OR') is taken to result in moments of conscious awareness and/or choice (Hameroff S, Penrose R. 2014 Consciousness in the universe: a review of the 'Orch OR' theory. Phys Life Rev 11(1): 39-78. Doi: 10.1016/j.plrev.2013.08.002. Epub 2013 Aug 20). Orch-OR operates in principle in protein tubules of neurons. This concept is non-computational and has received much attention with a convincing advocacy and its share of criticism. The advocacy includes the fossil record of organisms that emerged throughout the first Cambrian period with onset roughly 540 million years ago (mya). They had essential degrees of microtubular arrays in skeletal size, complexity and capability for quantum isolation. Attractive as this hypothesis maybe we point out that the brain is predominantly made of lipid not protein. We suggest that both protein and RNA in the brain would more likely been required to serve the extraordinary energy requirements for the brain. Early photosynthetic systems such as the dinoflagellates are rich in docosahexaenoic acid (DHA) including di-DHA phosphoglycerides as also in contemporary mammalian photoreceptors. We wish to discuss in Part II, quantum mechanical properties of the $\pi$-electrons of DHA suggestive of a mechanism for the depolarization of the receptor membrane at a precise energy levels as required for vision and neural signalling (Crawford MA, Broadhurst CL, Guest M et al., 2013. A quantum theory for the irreplaceable role of docosahexaenoic acid in neural cell signalling throughout evolution. Prostaglandins Leukot Essent Fatty Acids (PLEFA) 88(1): 5-13. Doi: 10.1016/j.plefa.2012.08.005. PMID: 23206328). We wish to extend this principle to a concept of brain function in learning, recall, perception and cognition.
\end{abstract}

Keywords: brain function / docosahexaenoic acid / signaling / tubules / food / quantum mechanics

\footnotetext{
^ The 2015 Chevreul Medal lecture, Lipids and Brain III Conference

*Corresponding author: michael.crawford@imperial.ac.uk
} 


\begin{abstract}
Résumé - Une théorie sur le rôle des électrons $\pi$ de l'acide docosahexaénoïque dans la fonction cérébrale (Partie I). Quelques points de vue sur le fonctionnement du cerveau. Dans la partie I de cet article, nous discuterons des bases du fonctionnement cérébral et de notre thèse selon laquelle il est conduit par des électrons $\pi$ qui assurent la réception sensorielle, la mémoire, l'activité, la cognition et la conscience. Notre théorie est cohérente avec les théories classiques sur les mouvements ioniques et le renforcement par les protéines synaptiques. Cependant, les théories basées sur les protéines ne contiennent pas d'éléments de précision suffisants pour expliquer le signal. La notion de précision est essentielle pour obtenir un signal correct de transduction à partir de l'induction sensorielle, et une exécution fidèle des voies neurales apprises. Dans la partie II, nous utiliserons ces principes pour discuter des mécanismes par lesquels la fonction des électrons ajoute de la précision au signal énergétique du système, par le biais du principe d'exclusion de Pauli. Le modèle de fonctionnement neuronal de Huxley-Hodgkin $(\mathrm{HH})$ décrit les mouvements des ions sodium, potassium et calcium pour créer les potentiels électrochimiques trans-membranaires selon des théories mathématiques et des expérimentations largement confirmées. Pour expliquer l'apprentissage, la conscience et la perception, d'autres ont proposé que la fonction cérébrale dépende de la synthèse protéique et du codage de l'ARN. D'autres encore considèrent la superposition et le collapsus comme un mécanisme computationnel, comparable à celui réalisé par un ordinateur. Cependant, cette hypothèse demeure fragile et sans description de mécanismes qui devraient limiter les phénomènes de collapsus et de décohérence susceptibles d'être obtenus à la température du cerveau. Une approche originale a été adoptée par Penrose et Hammeroff qui décrivent la conscience comme une fonction de « réduction objective $(\mathrm{OR})$ » de l'état quantique. L'orchestration de cette activité OR (Orch OR) est considérée comme résultant de moments d'attention consciente et/ou de choix. Elle se réalise en partie dans les tubules protéiques des neurones. Ce concept non-computationnel a soulevé beaucoup d'intérêt, apportant à la fois des arguments convaincants et des critiques. Les arguments favorables font appel aux connaissances sur les fossiles d'organismes de plus de 540 millions d'années issus du Cambrien primaire qui présentent un réseau complexe de microtubules. Aussi attractive que puisse être cette hypothèse, le cerveau est essentiellement composé de lipides et non de protéines. Nous postulons que les protéines comme l'ARN interviendraient plus probablement pour répondre aux énormes besoins énergétiques du cerveau. Les organismes vivants primaires utilisant la photosynthèse, comme les dinoflagellés, se révèlent riches en DHA (y compris en DHAphosphoglycérides), de même que les photorécepteurs des mammifères contemporains. Nous discuterons dans la partie II des propriétés quantiques des électrons $\pi$ du DHA, suggérant un mécanisme de dépolarisation des récepteurs membranaires à un niveau précis d'énergie, comme requis pour la vision et la signalisation neuronale. Nous voulons étendre ce principe à un concept plus général de fonctionnement du cerveau dans l'apprentissage, la mémorisation, la perception et la cognition.
\end{abstract}

Mots clés : fonction cérébrale / DHA / signal / tubules / alimentation / mécanismes quantiques

\section{Introduction}

\subsection{The law of induction}

Our thesis is that the brain is a non-computable, electromagnetic wave machine governed by quantum mechanical principles. Our thesis starts with the MaxwellFaraday's law of induction.

Maxwell-Faraday equation:

$$
\nabla \times \mathbf{E}=-\frac{1}{c} \frac{\partial \mathbf{B}}{\partial t}
$$

Symbols in bold represent vector quantities, and symbols in italics represent scalar quantities, unless indicated. $\mathrm{E}$ is the electric field, B the magnetic field. Whilst $\mathrm{E}$ is a vector, $\mathrm{B}$ is a pseudo vector field ${ }^{1}$.

The operation of induction at the macro level can be taken to operate at the micro level of the neural circuits. Such action would result in the harmonization of specific wave packets or forms which could constitute memory or an association. The Maxwell-Faraday's equation describes how a magnetic field induces an electric field in a time function. We propose that electromagnetic induction is the operating principle behind associations within the neural circuitry. There is however a fundamental difference. The current cannot be free flowing as in a dynamo. It needs to be constrained to operate at a fixed energy level as in semi-conduction to provide precision for the signal. Without precision, the execution of a neural circuit would blur and lose meaning. In Part I, we review some of the background proposals for brain function. In Part II, we present out theory of how the brain works based on electron movement rather than protein synthesis. We do not dispute the role of the protein synaptic strengthening and include that as part of our thesis. However, we suggest the thesis, that it is electron behaviour governed by quantum mechanical principles, that does the work of signalling.

\subsection{Properties of an electron}

Our thesis then is based on the energy levels of atomic electrons being affected by the electron spin magnetic moment and the orbital angular momentum of the electron ${ }^{2}$. A magnetic field caused by the electron's orbital motion interacts with the spin magnetic moment. This effective magnetic field can be expressed

\footnotetext{
${ }^{1}$ With acknowledgment and thanks to Wikipedia.
}

$\overline{{ }^{2} \text { Hydrogen Fine Structure, }} 2016$. 
in terms of the electron orbital angular momentum. The interaction energy is that of a magnetic dipole in a magnetic field:

$$
\mathrm{E}=\vec{\mu} \cdot \overrightarrow{\mathrm{B}}
$$

where $\mathrm{E}$ is the energy, $\mu$ is from the electron spin and $\mathrm{B}$ from the orbital motion.

The classical magnetic field in the electron frame $^{3}$ of reference arising from the orbital motion is:

$$
B=\frac{\mu_{0} Z e v}{4 \pi r^{2}} .
$$

The spin-orbit interaction is also a magnetic interaction, but with the magnetic field generated by the orbital motion of an electron within the atom itself. It has been described as an "internal Zeeman effect"4. This Zeeman effect describes the phenomenon when the magnetic fields are small enough that the orbital and spin angular momenta can be considered as coupled.

The energy of an electron can be calculated from:

$$
\mathrm{E}=-13.6 \mathrm{ev} / \mathrm{n}^{2} \text {. }
$$

Hydrogen and carbon are the two commonest elements in biology. In classical chemistry, electrons are considered to be in orbit around the positive nuclei. Two carbons are joined by sharing a pair of electrons to form a sigma bond. Hydrogen is joined to carbon by sharing one electron. Two adjacent carbons can share a second pair of electrons with the two outer orbitals overlapping making a double bond around both carbon atoms. These are the $\pi$ electrons, each of which has different quantum properties.

The Pauli Exclusion Principle states that no two electrons in the same orbit can have the same values of the four quantum numbers: $\mathrm{n}$, the principal quantum number, $\ell$, the angular momentum quantum number, $\mathrm{m} \ell$, the magnetic quantum number, and $\mathrm{ms}$, the spin quantum number.

In some respects, electrons, which are fermions, may be considered as identical. To solve their so-called identity we need to use a linear combination of the two possibilities. However, it is not possible to determine which electron is in which state. The wave function for the state in which both states "a" and "b" are occupied by the electrons can be written (HyperPhysics, 2016) for an electron:

$$
\Psi=\Psi_{1}(a) \Psi_{2}(b)-\Psi_{1}(b) \Psi_{2}(a),
$$

where $\Psi$ is the probability that both states are occupied by electrons 1 and 2 .

We will come this non-identity when we come to discuss the electron flow in the exercise of the brain.

The confinement of an electron in a box requires energy, the smaller the box the greater the energy. High energy scattering from electrons shows no "size" of the electron down to a resolution of about $10^{-3}$ fermis, and at that size a preposterously high spin rate of some $10^{32} \mathrm{radian} / \mathrm{s}$ would be required to match the observed angular momentum (HyperPhysics, 2016). It is like dealing with ghosts which is another way of looking at the Heisenberg Uncertainty Principle.

\footnotetext{
$\overline{3}$ http://hyperphysics.phy-astr.gsu.edu/hbase/quantum/hydfin. html\#c4.

${ }^{4}$ When atomic spectral lines are split by the application of an external magnetic field, it is called the Zeeman effect.
}

In Part II, we will speculate that it is the unique quantum mechanical property of the $\pi$-electrons to act as electromagnetic waves governed by the Heisenberg Uncertainly and Pauli Exclusion Principles, which are the basis of information storage, memory, recall and perception.

We will suggest that Clarke-Maxwell induction provides the means for communication in the brain. The Clarke Maxwell induction would at the atomic level of neural function be expressed as harmonic relationships between different parts of say a memory.

We also suggest that the precision so essential to faithful neural translation of photoreception, memory and recall is based on the Pauli Exclusion Principle which governs the waves of electromagnetic current flow.

We by no means claim to have all the answers and feel weak in the face of the principles that are operating to provide us with our memories and recall-never mind perception. We put this thesis forward in the hope that others may find something of interest here worth further exploration.

\section{Various concepts in quantum mechanics and brain function}

\subsection{Functionalist methodologies}

The suggestion that brain function is dependent on quantum mechanical considerations is not new (Nanopoulos, 1995; Walker, 2000; Mould, 2003; Conte et al., 2009; Hameroff and Penrose, 2014b). Quantum calculation has been described as dependent on superposed states executing different calculations at the same time, in parallel, as per quantum direct superposition (Benioff, 1982; Feynman, 1986; Deutsch and Jozsa, 1992). On a basic level, quantum processing is equipped for particular applications past the scope of established computation (Shor, 1994). Various innovative frameworks attempting to understand these propositions have been recommended and assessed as principles for quantum computers (e.g., caught particles, electron turns, quantum dabs, atomic twists (see Table 1 in Bennett, 1995). The primary hindrance to acknowledgment of quantum calculation is the issue of interfacing to the framework (info, yield) while additionally shielding the quantum state from natural decoherence at the warm temperatures of the brain. In these systems, the brain is conceived as operating as a computable machine except for Hammerhoff and Penrose who consider brain function to operate in a non-computable manner.

The workings of the human personality have been generally portrayed as analogies of contemporary data innovation. For sure baffling elements of cognizance have as of now prompted recommendations for quantum processing in the mind to mimic brain fufunction.

Commonly, attempts have been made to clarify awareness as a property of the PC in for example: functionalism, reductionism, physicality, realism and mathematical calculations (Churchland, 1986; Dennett, 1991; Churchland and Sejnowski, 1992). The present driving possibility for a PC like "neural connect" of awareness includes neuronal circuits wavering synchronously in thalamus and the cerebral cortex. Higher recurrence motions (on the whole known as "rational $40 \mathrm{~Hz}$ ") are proposed to integrate cognizant experience (Crick and Koch, 1990; Joliot et al., 1994; Gray, 1998; Walker, 2000). The ideas on localization vary, for instance with reference to whether initiation begins in the 
thalamus or the cortex. None the less, "thalamo-cortical $40 \mathrm{~Hz}$ " remains as a dominant perspective of the neural-level substrate for cognizance.

How then, do neural firings lead to musings and emotions and consciousness? Customary ("functionalist") methodologies miss the mark on the mind's confounding components by considering only one or two states. The many states of brain function include:

- the nature of subjective experience, or qualia, our "inward life" (Nagel, 1974; Chalmers, 1996);

- "coupling" of spatially circulated exercises into unitary articles in vision and a reasonable feeling of "self";

- movement from pre-cognizant handling to awareness;

- non-calculability (Penrose, 1989, 994, 1997);

- unrestrained choice-free will;

- precision of the signal.

Functionalist approaches by and large expect that cognizant experience shows up as a novel property at a basic level of computational multifaceted nature. At first glance this would appear to manage issues 1 and 3, however a cognizant limit has not been distinguished nor anticipated.

To address these issues, different propositions have been recommended in which naturally visible quantum marvels are associated with the cerebrum's known neural action. For the issue of unitary tying, Marshall (1989) recommended that rational quantum states known as Bose-Einstein buildup occurred among neural proteins. James Di Carlo et al. consider recognition, for example, is consequent on a computational algorithm which

"is solved in the brain via a cascade of reflexive, largely

feedforward computations that culminate in a powerful neuronal representation in the inferior temporal cortex. However, the algorithm that produces this solution remains little-understood." (DiCarlo et al., 2012).

The matter has been pursued enthusiastically in primates and rats and progress has been recently reviewed by Davide Zoccolan (Zoccolan, 2015).

These computational avenues can be independent of whether or not the mechanism is protein based or something else. They basically involve PC like computation. However, the use of neural proteins in one form or another has been commonly promoted (Penrose, 1987; Bohm and Hiley, 1993; Jibu and Yasue, 1995). This focus on protein in the brain is in our view wrong as it has little to offer to solve the critical "precision problem" to which we shall refer later.

\subsection{The orch/or concept of Penrose and Hammerhoff}

Mainstream theories of brain function essentially consider the mechanism of consciousness and brain function to be analogous to computation by a computer (Hodgkin and Huxley, 1952). Hence, the multibillion EURO investment to simulate brain function based on PC like computations ${ }^{5}$.

\footnotetext{
${ }^{5}$ Horizon 2020 is the largest EU Research and Innovation programme to date, with almost EUR 80 billion of funding available over seven years (2014-2020). This programme implements FET Flagships, such as the Human Brain Project. These are long-term, large-scale research initiatives aiming to solve ambitious challenges.
}

By contrast, Penrose and Hammerhoff claim that consciousness and therefore brain function is non-computable. In describing their view it is perhaps best to quote

"consciousness depends on biologically 'orchestrated' coherent quantum processes in collections of microtubules within brain neurons, that these quantum processes correlate with, and regulate, neuronal synaptic and membrane activity, and that the continuous Schrödinger evolution of each such process terminates in accordance with the specific Diósi-Penrose (DP) scheme of 'objective reduction' ('OR') of the quantum state. This orchestrated OR activity ('Orch OR') is taken to result in moments of conscious awareness and/or choice" (Hameroff and Penrose, 2014a).

Objective reductions are events which reconfigure the fine scale of space-time geometry. As described below, modern panpsychists attribute proto-conscious experience to a fundamental property of physical reality. If so, consciousness might involve self-organizing OR events rippling through an experiential medium.

Could OR events be occurring within the brain? If so they would be expected to coincide with best-known neuroscience processes with recognized time scales. The vital degree of spacetime separation supporting Penrose's objective reduction is explained by quantum gravity and the uncertainty principle:

$$
E=\operatorname{hbar} \Psi / T
$$

where $\mathrm{E}$ is the gravitational self-energy of the superposed mass (uprooted from itself by e.g. the breadth of its nuclear cores), hbar is Planck's constant and T is the rationality time until OR self-collapse.

Plank distance $\approx 10^{-35} \mathrm{M}$

Plank Time $\approx 10^{-43} \mathrm{sec}$

The span of a segregated superposed framework is subsequently identified, either/or with the time allotment until self-collapse. Vast superposed frameworks (e.g., Schrödinger's legendary cat in a box) would self-collapse (OR) in just $1037 \mathrm{sec}$; a segregated superposed iota would OR strictly after 106 years! In the event that an OR occasion happens in the cerebrum, coupled to known neurophysiology, we can gauge that $\mathrm{T}$ for a cognizant $\mathrm{OR}$ occasion may be in a reach from $10^{500}$ milliseconds (msec). This extent covers neurophysiological events, for example, $25 \mathrm{msec}$ "intelligible $40 \mathrm{~Hz}$ ", $100 \mathrm{msec}$ EEG rhythms, and Libet's (1979) $500 \mathrm{msec}$ tactile discernments. Then again occasions coupled to around $100 \mathrm{msec}$ events would require a couple of nanograms of superposed mass: energy being equivalent to mass.

$$
E=h b a r / t \text {. }
$$

Penrose and Hammerhoff side with quantum mechanical processes in proteins tubules and consider the process of consciousness to be non-computable. If thought processes were computational then the EU computer simulation itself, if successful, would have consciousness. Penrose comments in his talk that ethically, you would then have to ask it if you could turn it off! They also concede that whatever physical action is taking place is beyond present day physics.

These ideas have not escaped strong criticism from the computational people to which Hammerhoff and Penrose 
wrote a spirited reply (Hameroff and Penrose, 2014b). Sir Roger Penrose presented his hypothesis "Consciousness and the Foundations of Physics", delivered at the Ian Ramsey Centre-Humane Philosophy Project 2014-2015 Seminar on the 15th May, 2015, chaired by Ralph Weir, Alister McGrath and Mikolaj Slawkowski-Rode (Penrose, 2015).

Awareness and consciousness are fundamental properties of the nervous system. If this is correct then to simulate consciousness in a computable manner should be a small and simple matter. The honeybee has only a tiny number of neurons, but which enable it to achieve significant feats of learning, communication, co-operation, group self-identity and navigation. They are conscious of the apparent movement of the sun. In communicating the new-found location of nectar, they offset their information transmission (a dance) to cater for the movement of the hive in relation to the position of the sun. If such consciences, learning and communication process can be conducted by such a small number of neurons, then it should not require investment in hyper- super-computers. This example suggests to us along with Penrose that there is a physics at work which we have yet to fathom and understand "What physics is it?" he asks ${ }^{6}$.

Our thesis is similar to that of Penrose and Hammerhoff except instead of using protein tubules we use the electromagnetic properties of the synaptic membrane lipids. Lipids constitute the bulk of the brain, not protein. Moreover, our proposition deals with the signal, precision problem as we will discuss.

\subsection{Recent thoughts}

Quantum physicist, John Hagelin, moves into a completely different perspective of transcendental meditation (Hagelin, 2014). He describes quantum mechanics as many different wave functions operating in the brain in terms of many vibrational frequencies each with a different energy. Different energy means different mass. Therefore with different amounts of mass, one acts like gravity, another light, another an electron. Hence, consciousness is a unified field containing nature's code and a pathway to access consciousness comes through transcendental meditation. In that he makes use of Samadhi meditative state Alpha $(8-10 \mathrm{~Hz})$, he likens physics to philosophies such as Vaikhari is similar to classical physics, quantum mechanics to Madhyama, and quantum field theory to Pashyanti

Whilst discussing the world of the very small in quantum mechanical terms, his approach may seem outlandish to some as it sheds no light on the mechanism whereby consciousness is achieved. Nonetheless, it reflects the quantum world where actually, so little is fixed. An atom is not surrounded by a wall. A row or cluster of atoms have no walls between them or at the edge of the cluster. Yet in the larger world, they form a hard mass like iron. When thinking about how the brain might work, we are in the world of small dimensions and so have think in terms of fields and try to imagine how those fields might interact. Hagalin comes close to us by describing the analogy of an elastic band and its great number of vibrational states. He

\footnotetext{
${ }^{6}$ See also Hammerhoff on the same subject: https://www.youtube. com/watch? $v=1 d 5$ RetvkkuQ Hammerhoff TED Lecture.
}

talks of fields having their own vibrational states or tone. These can be seen in the EEG under different condition such as:

- active focus on an issue with high amplitude gamma and the electrical activity telling us that many things are happening. There is seething electrical phenomenon. Regions of the brain talk to each other;

- monitoring function - which gives a completely different pattern of electron wave activity;

- in Transcendental Meditation, the electrical activity is again quite different. Here the brain is functioning in an integrated way which you do not see in anaesthesia, deep sleep or under the influence of drugs.

\section{Are proteins the basis of brain function?}

We have previously commented that the above concepts of consciousness and brain function, Hagelin excepted, focus on proteins. These are flexible macromolecules which perform a mixed bag of capacities by changing their conformational shape. Such capacities incorporate muscle development and function, layer termination by means of openings and closings of ion and particle channels, sub-atomic tying, receptor function, catalysis and digestion and indeed recognition of chemicals.

Single proteins are orchestrated as chains of several amino acids which fold into 3 dimensional compliance. The exact way of collapsing for every protein relies on upon attractive and repellent powers among its different amino acid regions that evolved to be fit for purpose (Baldwin, 1994). One idea, is that a protein collapsing is a quantum calculation.

In an aqueous medium, the fundamental main thrust in protein collapse happens as uncharged non-polar gatherings of specific amino acids join together and evade water. Repulsed by dissolvable water, "hydrophobic" non-polar gatherings draw into one another (by van der Waals forces) and cover themselves inside the protein. Accordingly, intra-protein hydrophobic pockets occur. Volumes of the pockets $(\sim 400$ cubic angstroms, or 0.4 cubic nanometers) are approximately $1 / 30$ to $1 / 250$ the aggregate volume of an individual protein. The physical properties of the region are somewhat similar to olive oil. This process leaves the maximum number of watersoluble amino acids in contact with the surrounding water. However, least researched is the converse of the lipophilic proteins behaving much the same but opposite way to make contact and live with the membrane lipids.

Proteins and indeed lipids in a living state are in continuous dynamic motion. These movements include aggregate activities of different intra-protein exercises (e.g., hydrogen bond adjustments, dipole motions, van der Waals powers). They have the potential to generate ionic interactions and hydrogen bonding. There are many dipole moments within a protein and cooperation between dipoles offers interesting electrical properties utilized for example in the electron transfer system for energy production in mitochondria.

Most detailed molecular structure has been determined by x-ray crystallography for proteins. Cell membranes however contain lipophilic proteins that are almost impossible to extract in a manner which allows x-ray crystallography to describe their properties in a living cell. 
Here for a start is a major unknown, especially as the brain is a lipid rich organ. The question is could the neuron proteins constitute neural function learning, recognition, random thoughts, dreams, perception and cognition when they have to sub-serve, ion movement, transport substrates, defend against peroxidation and especially provide the great energy production needed to push ions against concentration gradients, maintain myelin sheaths and dendrite/synapse integrity and much else involved in the material of brain maintenance? The adult brain uses $20 \%$ of the body's total energy use although it only is $2 \%$ of the body mass. Even more surprisingly, much of the $2 \%$ weight that accounts for the brain comes from non-metabolically active systems such as the myelin sheaths. The actual oxygen/energy use by the metabolically active components must be huge.

The significance of the hydrophobic/lipophilic attributes of neural proteins is thought to be behind the anaesthetic properties of certain gases. Notably, these reversibly remove cognizance: to all intents and purposes shutting the brain down into an unconscious state.

It is thought that unconsciousness happens through disorienting hydrophobic pockets of neural protein (Franks and Lieb, 1985). Why might one ask are these frail, restricted communications so imperative to protein capacity and cognizance? The answer is, they may not be! The missing feature in the discussion on proteins is not only the lipophilic regions of the protein but the fact that many are intimately tied to membrane lipids. Hence, the impact of anesthetic gases often being lipophilic is just as likely an impact on the signaling membrane lipids as it is on the protein. If the 3-D structure of the protein is affected, then the lipid will also be influenced and vice versa.

\section{Excitability}

Excitability is still a question. The widely-accepted view is the Hodgkin-Huxley formula describing the action potential, polarization and depolarization of impulse transmission. In it, proteins control permeability for $\mathrm{Na}^{+}$and $\mathrm{K}^{+}$, or $\mathrm{Ca}^{2+}$, e.g. $3 \mathrm{Na}^{+}: 1 \mathrm{Ca}^{2+}$.

However, an alternative to HH model was Goldman's suggestion that the membrane dipole moment controlled ion movement (Tamagawa and Ikeda, 2017). There is also evidence for super-conductivity associated with nerve impulses (Cope, 1973). To cap it all, chloroform has been shown to increase the capacitance of planar lipid bi-layers (Fernandez et al., 1982). This point highlights our idea that the lipid membrane can act as a capacitor as we will discuss in Part II. It is interesting that docosahexaenoic acid which is a dominant acyl component of the SN2 position of the photoreceptor, synaptic and neuronal cell membranes can be planar. However, the docosapentaenoic acid, a precursor with one less double bond, cannot be made planar (Crawford et al., 1999). As far as we know to date, docosapentaenoic acid has never replaced docosahexaenoic acid in the photoreceptor, synapse and neurons throughout the evolution of the eukaryotes (Crawford et al., 2013).

Chloroform anesthesia amounts to loss of consciousness. The converse, is conduction across the membrane. Consequently, it is just as likely that the removal of cognizance by chloroform and other anesthesia is a function of an unusual, conduction property of membrane lipids which is what we propose.

We do not dispute the HH model as there must be a system for generating potential differences to activate electrons. At the same time, it is difficult to imagine that the electrons pay no attention to the substantial potential differences created by the $\mathrm{HH}$ model. Moreover, electrons can do much more and many times faster than migrating potassium, calcium or especially, sodium ions with their large shell of water of hydration.

We suggest the job of the proteins is their known function in energy production, protection from peroxidation and the tying of lipids in the membranes. Note the very high concentration of mitochondria in the cell body of the photoreceptor! In contrast, the bulk of the brain is a highly specialized fat-some $60 \%$. Our thesis is that learning, recall, recognition, random thoughts, dreams, perception and cognition are functions of the $\pi$-electrons of these highly specialized neural lipids which are served by the proteins.

\section{The need for precision of the signal}

Protein strengthening of the synapse is now accepted as the explanation for memory based on good evidence. By itself, enhancing protein synthesis is well documented but it does not appear a priori to confer precision to the signal. That precision is essential can be seen by considering a situation in which two photoreceptors respond differently to the same incoming wavelength. The effect would be a blur. Studies with single photons have provided evidence that the energy output is quantized: "At wavelengths between 420 and $700 \mathrm{~nm}$, the quantal event was invariant in size": it is the same regardless of the energy input from the photon (Baylor et al., 1979). That is, there is high degree of precision involved in the sensory input for vision. Lack of precision would mean lack of visual acuity. Interestingly, experiments aimed at depleting the DHA content of the photoreceptor and the brain result in alteration of electrical activity (Benolken et al., 1973) and loss of visual acuity (Neuringer et al., 1986). These studies include trials in preterm and term infants fed formula with and without DHA (Birch et al., 2010).

Similarly, it can be argued that high precision is required for the memory recall and execution of neural pathways. If there was no precision in the signal transmission, then the signal could wander, distorting the memory. It is difficult to understand how protein enhancement on its own of the synapses could provide for this high degree of precision required. In Part II, we will explore a concept whereby precision is guaranteed if the $\pi$-electrons are responsible for the signaling.

\section{Conclusion Part I}

In summary: we suggest there are three major problems in theories based on neuronal proteins:

- the primary job of the proteins in the brain is to provide for the phenomenal amount of energy required;

- the major structural component of the brain is lipid not protein;

- there is no explanation for the almost absolute precision required for visual acuity and truthfulness of recall or 
exercise of a neural pathway to be found in theories based on proteins. Yet absolute precision is essential to brain signaling otherwise the signal would be blurred and acuity lost.

In the second part, we will put forward a thesis based on the special quantum mechanical properties of the lipid $\pi$-electrons, which we shall explain can provide for the absolute precision required for photoreception, memory and consciousness.

Acknowledgements. We wish to express our appreciation for financial support underpinning the observations on DHA from the Mother and Child Foundation, the Waterloo Foundation, and from the late Professor Letten F Saugstad for her constant questioning of what DHA was doing in the brain, together with support from her Letten Foundation, as well as the late Professor Cedric Hassall FRS for his mentoring. We thank Wellohi for finance to help in the writing of this paper and Samuel Levine for his prompting and encouragement. We also thank The Société Française pour l'Étude des Lipides, Bernadette Delplanque and her colleagues for continuing support for lipid research and the Medale Chevreul.

\section{References}

Baldwin RL. 1994. Protein-folding-matching speed and stability. Nature 369(6477): 183-184.

Barenco A, Bennett CH, Cleve R, et al. 1995. Elementary gates for quantum computation. Phys Rev A 52(5): 3457.

Baylor DA, Lamb TD, Yau KW. 1979. Responses of retinal rods to single photons. J Physiol 288(1): 613-634.

Benioff P. 1982. Quantum mechanical Hamiltonian models of Turing machines. J Stat Phys 9(3): 515-546.

Bennett CH. 1995. Quantum information and computation. Phys Today 48(10): 24-31.

Benolken RM, Anderson RE, Wheeler TG. 1973. Membrane fatty acids associated with the electrical response in visual excitation. Science 182(118): 1253-1254.

Birch EE, Carlson SE, Hoffman DR, et al. 2010. The DIAMOND (DHA Intake And Measurement Of Neural Development) Study: a double-masked, randomized controlled clinical trial of the maturation of infant visual acuity as a function of the dietary level of docosahexaenoic acid. Am J Clin Nutr 91(4): 848-859.

Bohm D, Hiley BJ. 1993. The undevided universe: an ontological interpretation of quantum mechanics. London and New York: Routledge.

Chalmers DJ. 1996. The conscious mind: In search of a fundamental theory. Oxford (UK): Oxford University Press.

Churchland PS. 1986. Neurophilosophy: toward a unifiedscience of the mind-brain. MA (USA): MIT Press Cambridge.

Churchland PS, Sejnowski TJ. 1992. The computational brain. Cambridge, MA: MIT Press, 544 p. vol. 29, pp. 1665-1674.

Conte E, Khrennikov AY, Todarello O, Federici A, Mendolicchio L, Zbilut JP. 2009. Mental states follow quantum mechanics during perception and cognition of ambiguous figures. Open Syst Inf Dyn 16(01): 85-100.

Cope FW. 1973. Enhancement by high electric fields of superconduction in organic and biological solids at room temperature and a role in nerve conduction? Physiol Chem Phys 6(5): 405-410.
Crawford MA, Bloom M, Broadhurst CL, et al. 1999. Evidence for the unique function of docosahexaenoic acid during the evolution of the modern hominid brain. Lipids 34: S39-S47.

Crawford MA, Broadhurst CL, Guest M, et al. 2013. A quantum theory for the irreplaceable role of docosahexaenoic acid in neural cell signalling throughout evolution. Prostaglandins Leukot Essent Fatty Acids (PLEFA) 88(1): 5-13. Doi: 10.1016/ j.plefa.2012.08.005. PMID: 23206328.

Crick F, Koch C. 1990. Towards a neurobiological theory of consciousness. In: Seminars in the Neurosciences. Saunders Scientific Publications, vol. 2, pp. 263-275.

Dennett DC. 1991. Consciousness Explained. Boston: Little, Brown and $\mathrm{Co}$.

Deutsch D, Jozsa R. 1992. Rapid solution of problems by quantum computation. In: Proceedings of the Royal Society of London A: Mathematical, Physical and Engineering Sciences Dec 8. The Royal Society, vol. 439, no. 1907, pp. 553-558.

DiCarlo JJ, Zoccolan D, Rust NC. 2012. How does the brain solve visual object recognition? Neuron 73(3): 415-434.

Fernandez JM, Bezanilla F, Taylor RE. 1982. Effect of chloroform on charge movement in the nerve membrane. Nature 297(5862): $150-152$.

Feynman RP. 1986. Quantum mechanical computers. Found Phys 16 (6): 507-531.

Franks NP, Lieb WR. 1985. Mapping of general anaesthetic target sites provides a molecular basis for cutoff effects. Nature 316 (6026): 349-351.

Gray JA. 1998. Creeping up on the hard question of consciousness. Toward a Science of Consciousness II-The Second Tucson Discussions and Debates. In: Hameroff S, Kaszniak A, Scott A, eds. MA (USA): MIT Press Cambridge, pp. 279-291.

Hagelin J. 2014. Consciousness, a quantum physics perspective. Available from: https:/www.youtube.com/watch?v=RJ4Uv5_3VM, [Accessed 7th October 2017].

Hameroff S, Penrose R. 2014a. Consciousness in the universe: A review of the 'Orch OR' theory. Phys Life Rev 11(1): 39-78. Doi: 10.1016/j.plrev.2013.08.002. Epub 2013 Aug 20.

Hameroff S, Penrose R. 2014b. Reply to seven commentaries on "Consciousness in the universe: Review of the 'Orch OR'theory". Phys Life Rev 11(1): 94-100.

Hodgkin AL, Huxley AF. 1952. A quantitative description of membrane current and its application to conduction and excitation in nerve. J Physiol 117(4): 500-544.

HyperPhysics, 2016. Hydrogen Fine Structure. Available from http:// hyperphysics.phyastr.gsu.edu/hbase/quantum/hydfin.html\#c1.

Jibu M, Yasue K. 1995. Quantum brain dynamics and consciousness: an introduction. Amsterdam (Netherlands): John Benjamins Publishing.

Joliot M, Ribary U, Llinas R. 1994. Human oscillatory brain activity near $40 \mathrm{~Hz}$ coexists with cognitive temporal binding. Proc Natl Acad Sci U S A 91(24): 11748-11751.

Libet B. 1979. Subjective Referral of the timing for a conscious sensor experience: a functional role for the somatosensory specific projection system in man. Brain 194: 191-222.

Marshall IN. 1989. Consciousness and Bose-Einstein condensates. New Ideas Psychol 7(1): 73-83.

Mould RA. 2003. Quantum brain states. Found Phys 33(4): 591-612.

Nagel T. 1974 What is it like to be a bat? Philos Rev 83(4): 435-450.

Nanopoulos D. 1995. Theory of brain function, quantum mechanics and superstrings. Available from https://arxiv.org/pdf/hep-ph/ 9505374.pdf (last consult: 29/06/2017).

Neuringer M, Connor WE, Lin DS, Barstad L, Luck S. 1986. Biochemical and functional effects of prenatal and postnatal $\omega$ 
3 fatty acid deficiency on retina and brain in rhesus monkeys. Proc Natl Acad Sci U S A 83(11): 4021-4025.

Penrose R. 1987. Newton, quantum theory and reality. Three hundred years of gravitation. Cambridge (UK): Cambridge University Press pp. 17-49.

Penrose R. 1989. The Emperor's New Mind: concerning computers, brains and the laws of physics. Oxford: Oxford University Press.

Penrose R. 1994. Shadows of the Mind: an approach to the missing science of consciousness. Oxford: Oxford University Press.

Penrose R. 1997. On understanding understanding. Int Stud Philos Sci 11(1): 7-20.

Penrose R. 2015. "Consciousness and the foundations of physics". Available from: https://www.youtube.com/watch?v=eJjyd SLEVIU, [Accessed 7th October 2017].

Shor PW. 1994. Polynomial time algorithms for discrete logarithms and factoring on a quantum computer. In: International Algorithmic Number Theory Symposium May 6. Berlin, Heidelberg: Springer, pp. 289-289.

Tamagawa H, Ikeda K. 2017. Generation of membrane potential beyond the conceptual range of Donnan theory and GoldmanHodgkin-Katz equation. J Biol Phys. Doi: 10.1007/ s10867-017-9454-7.

Walker EH. 2000. The physics of consciousness. Cambridge: Perseus Publising, Mass, pp. 215-267.

Zoccolan D. 2015. Invariant visual object recognition and shape processing in rats. Behav Brain Res 285: 10-33.

\section{Further readings}

Atmanspacher H, Römer H, Walach H. 2002. Weak quantum theory: Complementarity and entanglement in physics and beyond. Found Phys 32(3): 379-406.

Atmanspacher H, Filk T, Römer H. 2006. January. Weak quantum theory: Formal framework and selected applications. In: AIP Conference Proceedings (Vol. 810, No. 1, pp. 34-46). AIP.

Bohr N. 1928. The quantum postulate and the recent development of atomic theory. Available from http://www.informationphilosopher. com/solutions/scientists/bohr/quantum_postulate.html (last consult: 29/06/2017).

Busemeyer JR, Wang Z. 2007. March. Quantum Information Processing Explanation for Interactions between Inferences and Decisions. In: AAAI Spring Symposium: Quantum Interaction (pp. 91-97).

Caulfield HJ, Shamir J. 1989. Wave particle duality considerations in optical computing. App Opt 28(12): 2184-2186.

Conte E, Khrennikov AY, Todarello O, et al. 2009. Mental states follow quantum mechanics during perception and cognition of ambiguous figures. Open Syst Inf Dyn 16(01): 85-100.

Dalla Chiara ML, Giuntini R, Greechie R. 2013. Reasoning in quantum theory: sharp and unsharp quantum logics (Vol. 22). Berlin (Germany): Springer Science \& Business Media.

Davies PC. 2004. Does quantum mechanics play a non-trivial role in life? Biosyst 78(1-3): 69-79.

Davies PC. 2004. Quantum fluctuations and life. In: Noise and Information in Nanoelectronics, Sensors, and Standards II (Vol. 5472, pp. 1-11). International Society for Optics and Photonics.

Deli E. 2017. Consciousness, a Cosmic Phenomenon - A Hypothesis. Sci GOD J 8(1): 24-42.

Di Biase F. 2016. Brain and Cosmos. The unified field of consciousness. Available from https://www.researchgate.net/profile/ Francisco_Di_Biase3/publication/309548333_The_Unified_Fiel d_of_Consciousness/links/5816236408aeb720f688060a/The-Uni fied-Field-of-Consciousness.pdf (last consult: 29/06/2017).
Dowling JP, Milburn J. 2003. Quantum technology: the second quantum revolution. Philos Trans $R$ Soc Lond A Math Phys Eng Sci 361(1809): 1655-1674.

Drieschner M, Görnitz T, von Weizsäcker CF. 1988. Reconstruction of abstract quantum theory. Int J Theor Phys 27(3): 289-306.

Eagle CT. 1991. Steps to a theory of quantum therapy. Music Ther Perspect 9(1): 56-60.

Ellis GF. 2012. On the limits of quantum theory: Contextuality and the quantum-classical cut. Ann Phys 327(7): 1890-1932.

Faye J. 2002. Copenhagen interpretation of quantum mechanics. Available from https://seop.illc.uva.nl/entries/qm-copenhagen/ (last consult: 29/06/2017).

Gamow G. 1985. Thirty years that shook physics: The story of quantum theory. Massachusetts (US): Courier Corporation.

Giuliani G, Vignale G. 2005. Quantum theory of the electron liquid. Cambridge (UK): Cambridge university press.

Hagan S, Hameroff SR, Tuszyński JA. 2002. Quantum computation in brain microtubules: Decoherence and biological feasibility. Phys Rev E 65(6): 061901.

Haldane JBS. 1934. Quantum mechanics as a basis for philosophy. Philos Sci 1(1): 78-98.

Harris KD, Shepherd GMG. 2015. The neocortical circuit: themes and variations. Nat Neurosci 18(2): 170-181. Doi: 10.1038/nn.3917.

Jahn RG, Dunne BJ. 1986. On the quantum mechanics of consciousness, with application to anomalous phenomena. Found Phys 16(8): 721-772.

Joos E, Zeh HD, Kiefer C, Giulini DJ, et al. 2013. Decoherence and the appearance of a classical world in quantum theory. Berlin (Germany): Springer Science \& Business Media.

Krishnamurthy EV, Krishnamurthy V. 2001. Quantum field theory and computational paradigms. Int J Mod Phys C 12(08): 1179-1205.

Li D, Du Y. 2007. Artificial intelligence with uncertainty. Boca Raton (USA): CRC press.

Margenau H. 1950. The nature of physical reality: A philosophy of modern physics. Woodbridge (US): Ox Bow Press.

McEvoy JP, Zarate O. 2014. Introducing quantum theory: A graphic guide. London (UK): Icon Books Ltd.

Mitin VV, Kochelap V, Stroscio MA. 1999. Quantum heterostructures: microelectronics and optoelectronics. Cambridge (UK): Cambridge University Press.

Moreira C, Wichert A, 2015. The synchronicity principle under quantum probabilistic inferences. NeuroQuantology. Available from https://www.neuroquantology.com/index.php/journal/article/view/ 788/698 (last consult: 29/06/2017).

Mould RA. 2003. Quantum Brain States. Found Phys 33(4): 591-612. Murray T. 2008. Exploring Epistemic wisdom: Ethical and practical implications of integral theory and methodological pluralism for collaboration and knowledge-building. In: 1st Biannual Integral Theory Conference, John F. Kennedy University. Pleasant Hill, CA. Musso CG, Francisco Baez MD, Elias MJ, Schpilberg M. 2017. The principle of synchronicity-equivalence and chronomedicine: relevance and methodological exploration. Arch Argent Pediatr 115(4): 309-310.

Nanopoulos D. 1995. Theory of brain function, quantum mechanics and superstrings. arXiv preprint hep-ph/9505374.

Perlovsky LI. 2002. Physical theory of information processing in the mind: Concepts and emotions. SEED 2(2): 36-54.

Peters D, Peters J, 1981. Quantum theory of the structure and bonding in proteins: Part 8. The alanine dipeptide. J Mol Struct THEOCHEM 85(1-2): 107-123. Doi: 10.1016/0166-1280(81)85054-3.

Piotrowski EW, Sladkowski J. 2003. The next stage: quantum game theory. arXiv preprint quant-ph/0308027. 
Polkinghorne J. 2002. Quantum theory: A very short introduction. Oxford (UK): Oxford University Press..

Popper KR. 1992. Quantum theory and the schism in physics (Vol. 3). Hove (UK): Psychology Press.

Resconi G, Kovalerchuk B. 2010. Agents in quantum and neural uncertainty. Multi-Agent Applications for Evolutionary Computation and Biologically Inspired Technologies. Hershey, New York: IGI Global, pp. 50-76.

Soros G. 2013. Fallibility, reflexivity, and the human uncertainty principle. J Econ Methodol 20(4): 309-329.

Stapp HP. 2004. Whiteheadian process and quantum theory. Physics and Whitehead-Quantum, Process, and Experience. New York: SUNY Press, pp. 92-102.

Stern A. 1994. The quantum brain: theory and implications. Newnes. Amsterdam (Netherlands): Elsevier.

Stern A. 2000. Quantum Theoretic Machines: What is thought from the point of view of Physics? Amsterdam (Netherlands): Elsevier.

Svozil K. 1996. Quantum algorithmic information theory. J Univers Comput Sci 2(5): 311-346.
Vitiello G. 2001. My double Unveiled: the dissipative quantum model of brain (Vol. 32). Amsterdam (Netherlands): John Benjamins Publishing. Waldner D. 2017. Schrödinger's Cat and the Dog That Didn't Bark: Why Quantum Mechanics is (Probably) Irrelevant to the Social Sciences. Critic Rev 29(2): 199-233.

Walker EH. 2000. The physics of consciousness: The quantum mind and the meaning of life. Cambridge, MA: Perseus.

Walker EH. 2016. Consciousess and Quantum Theory (Vol. 23). New York (US): Cosimo, Inc.

Wang Z, Busemeyer JR, Atmanspacher H, Pothos EM. 2013. The potential of using quantum theory to build models of cognition. Top Cogn Sci 5(4): 672-688.

Wheeler JA. 1974. Perspectives: The Universe as Home for Man: Puzzles attached to consciousness, the quantum principle, and how the universe came into being suggest that the greatest discoveries are yet to come. Am Sci 62(6): 683-691.

Wheeler JA, Zurek WH, eds. 2014. Quantum theory and measurement. Princeton (US): Princeton University Press.

Yates FE. 1980. Physical causality and brain theories. Am J Physiol-Regul Integr Comp Physiol 238(5): R277-R290.

Cite this article as: Crawford M, Thabet M, Wang Y. 2018. An introduction to a theory on the role of $\pi$-electrons of docosahexaenoic acid in brain function. OCL 25(4): A402. 